\title{
THE IMPACT OF BRAZILIAN SAMBA ON PARKINSON'S DISEASE: ANALYSIS BY THE DISEASE SUBTYPES
}

\author{
O IMPACTO DO SAMBA BRASILEIRO NA DOENÇA DE PARKINSON: ANÁLISE ATRAVÉS DOS SUBTIPOS \\ DADOENÇA
}

Original Article

ARTIGO ORIGINAL

Artículo Original

\section{EL IMPACTO DEL SAMBA BRASILEÑO EN LA ENFERMEDAD DE PARKINSON: ANÁLISIS A TRAVÉS DE LOS SUBTIPOS DE LA ENFERMEDAD}

\begin{abstract}
Ana Cristina Tillmann' (1D (Physical Education Professional) Alessandra Swarowsky² (DD (Physiotherapist)

Alexandro Andrade 1 (ID) (Physical Education Professional) Jéssica Moratelli' (ID) (Physical Education Professional) Leonessa Boing' (iD) (Physical Education Professional) Melissa de Carvalho Souza Vieira' (ID) (Physical Education Professional) Alice Erwig Leitão' ${ }^{1}$ (D) (Physical Education Professional) Adriana Coutinho de Azevedo Guimarães ${ }^{1}$ (ID) (Physical Education Professional)

1. Universidade do Estado de Santa Catarina (UDESC), Postgraduate Program in Sciences of Human Movement, Florianópolis, SC, Brazil. 2. Universidade do Estado de Santa Catarina (UDESC), Postgraduate Program in Physiotherapy,

Florianópolis, SC, Brazil.
\end{abstract}

\section{Correspondence:}

Jéssica Moratelli

Juan Carlos Manucci, 88, São José, Florianópolis, SC, Brazil. 88080-350. jessica.moratelli@hotmail.com

\begin{abstract}
Introduction: People with Parkinson's disease constantly have low levels of physical activity. Dancing has become increasingly important for treating the disease and can help improve non-motor symptoms. Objective: To analyze the influence of Brazilian samba on the non-motor symptoms of PD according to TD and PGID subtypes. Methods: A 12-week, non-randomized clinical trial, through comparison with a control group. The 23 individuals who agreed to participate in the activities formed the experimental group (EG) and the 24 individuals who opted not to participate in the Brazilian samba classes comprised the control group (CG). A questionnaire was applied, composed of validated instruments. Mini Mental State Examination - MMSE; HY - Disability Scale; Unified Parkinson's Disease Rating Scale - UPDRS 1 and total values; Parkinson's Disease Questionnaire - PDQ-39, Parkinson's Disease Sleep Scale - PDSS; Beck Depression Inventory - BDI; Fatigue Severity Scale - FSS and Magnitude of Perceived Changes. Results: After the twelve weeks of intervention, it was observed that the EG showed improvement in the scores of all the tests. The comparison between groups, however, indicated a significant difference in the post-UPDRS1 period in which the EG presented improvement in cognitive impairment, while the CG presented a deficit in these values. The results of the division between disease subtypes show a greater change in the values between individuals of the TD group, when comparing the EG with the CG. For the EG, the greatest difference between pre- and post- intervention was fatigue. Conclusion: There was a positive trend in all the variables studied after the application of the protocol. This demonstrates that interventions such as dance may have greater effects on non-motor symptoms, depending on the expected progression of the disease. The scarcity of studies that use this approach in their analyses may explain the lack of evidence in this symptomatology related to dance. Level of evidence Il; Therapeutic studies - Investigating the results of treatment.
\end{abstract}

Keywords: Dance; Non-Motor Symptoms; Parkinson Disease.

\section{RESUMO}

Introdução: As pessoas com doença de Parkinson constantemente apresentam baixos níveis de atividade física. A dança tem se tornado cada vez mais importante para o tratamento da doença e pode ajudar a melhorar os sintomas não motores. Objetivo: Analisar a influência do samba brasileiro nos sintomas não motores da DP, segundo os subtipos TD ePGID. Métodos: Ensaio clínico não randomizado com duração de 12 semanas por meio de comparação com grupo controle. Os 23 individuos que aceitaram participar das atividades formaram o grupo experimental (GE) e os 24 individuos que optaram por não participar das aulas de dança brasileira formaram o grupo controle (GC). Um questionário foi aplicado, composto por instrumentos validados: Mini Exame do Estado Mental - MEEM; HY - Escala de Grau de Incapacidade; Escala Unificada de Avaliação da Doença de Parkinson - UPDRS 1 e valores totais; Questionário sobre a Doença de Parkinson-PDQ-39; Escala de Sono para a Doença de Parkinson-PDSS; Inventário de Depressão de Beck-BDI; Escala de Severidade de Fadiga - FSS e Magnitude das Alterações Percebidas. Resultados: Após doze semanas de intervenção, observou-se que o GE apresentou melhora nos escores de todos os testes. A comparação entre os grupos, no entanto, indicou uma diferença significativa no período pós-UPDRS1 em que o GE apresentou melhora no comprometimento cognitivo, enquanto o GC apresentou déficit nesses valores. Os resultados da divisão entre os subtipos da doença apresentam uma maior mudança nos valores entre os indivíduos do grupo TD ao comparar o GE com o GC. Em relação ao GE, a maior diferença entre a pré e pós-intervenção foi relacionada à fadiga. Conclusão: Houve tendência positiva em todas as variáveis estudadas após a aplicação do protocolo. Isso demonstra que intervenções como a dança podem ter maiores efeitos sobre os sintomas não motores, dependendo da progressão esperada da doença. A escassez de estudos que utilizam essa abordagem em suas análises pode explicar a falta de evidências nessa sintomatologia relacionadas à dança. Nível de evidência Il; Estudos terapêuticos-Investigação dos resultados do tratamento.

Descritores: Dança; Sintomas não motores; Doença de Parkinson.

\section{RESUMEN}

Introducción: Las personas con enfermedad de Parkinson constantemente presentan bajos niveles de actividad física. La danza se ha vuelto cada vez más importante para el tratamiento de la enfermedad y puede ayudar a mejorar 
los sintomas no motores. Objetivo: Analizar la influencia del samba brasileño en los sintomas no motores de la EP, según los subtipos TD y PGID. Métodos: Ensayo clínico no aleatorizado con duración de 12 semanas, por medio de comparación con grupo control. Los 23 individuos que aceptaron participar en las actividades formaron el grupo experimental (GE) y los 24 individuos que optaron por no participar en las clases de danza brasileña formaron el grupo control (GC). Fue aplicado un cuestionario, compuesto por instrumentos validados: Mini Examen del Estado Mental - MEEM; HY - Escala del Grado de Incapacidad; Escala unificada de evaluación de la Enfermedad de Parkinson - UPDRS 1 y valores totales; Cuestionario sobre la Enfermedad de Parkinson - PDQ-39; Escala de Sueño de la Enfermedad de Parkinson - PDSS; Inventario de Depresión de Beck - BDl; Escala de Severidad de la Fatiga - FSS y Magnitud de las Alteraciones Percibidas. Resultados: Después de doce semanas de intervención, se observó que el GE presentó una mejora en los puntajes de todos los tests. La comparación entre los grupos, sin embargo, indicó una diferencia significativa en el período post-UPDRS1 en que el GE presentó una mejora en el compromiso cognitivo, mientras que el GC presentó déficit en esos valores. Los resultados de la división entre los subtipos de la enfermedad presentan un mayor cambio en los valores entre los individuos del grupo TD al comparar el GE con el GC. Con relación al GE, la mayor diferencia encontrada entre la prey post intervención fue relacionada a la fatiga. Conclusión: Hubo tendencia positiva en todas las variables estudiadas después de la aplicación del protocolo. Eso demuestra que intervenciones como la danza pueden tener mayores efectos sobre los síntomas no motores, dependiendo de la progresión esperada de la enfermedad. La escasez de estudios que utilizan ese abordaje en sus análisis, puede explicar la falta de evidencias en es a sintomatología cuando relacionadas a la danza. Nivel de evidencia ll; Estudios terapéuticos - Investigación de los resultados del tratamiento.

Descriptores: Danzas; No motor Síntomas; Enfermedad de Parkinson.

\section{INTRODUCTION}

Parkinson's disease (PD) affects about 1\% of the world population; and although it is more associated with motor symptoms such as tremor, postural loss and balance, ${ }^{2}$ it also has marked non-motor symptoms such as depression, mood swings, ${ }^{3}$ fatigue reports ${ }^{4}$ cognitive deficits $^{5}$ and sleep disorders. ${ }^{6}$ Regarding PD, in the international panorama the last fifteen years were marked by evidence allowing distinguish the clinical manifestations by different morphological factors ${ }^{7}$ although based on the motor phenotype; also predict non-motor symptoms, namely dominant tremor (DT) and akinetic rigid or postural instability and gait difficulty (PIGD). ${ }^{8}$

In this perspective, disease characterization undertake to observe not only the individual symptoms, but to consider by the clinical subtypes perspectives, the disease progression in a longitudinal analysis $;{ }^{9}$ in which PIGD characteristics individuals exhibit predominant axial motor symptoms, more rapid deterioration of motor function, and non-motor symptoms in general prominent when compared to the TD subtype. ${ }^{10}$ Considerate these clinical values may help the treatment and impact quality of life of these patients, ${ }^{11}$ since drug treatment of non-motor symptoms can be challenging due the subjectivity of the manifestations ${ }^{12}$ and non-pharmacological options are underutilized due to limited knowledge about it is therapeutic potential in this symptomatology. ${ }^{13}$

The increasing number of evidence supporting the beneficial effects of non-drug therapy on non-motor symptoms, especially physical exercise in maintenance, encourages the creation of rehabilitation programs ${ }^{14}$ that seek through active interventions such as dance, ${ }^{15}$ gymnastics, ${ }^{16}$ and exercises planned individually ${ }^{17}$ or in groups, in order to increase treatment possibilities for this population. Toward there is a growing body of evidence supporting improvements in PD non-motor function with dance, and well-documented improvements in motor function. ${ }^{18}$

However, since there's still difficulties verifying significant effects in this symptomatology, biomarkers use to ascertain the interventions results may be a tool to better understand Parkinson's behavior to non-drug therapy and thus to predict and recommend the best approach to follow according to expected progression in each disease subtype.
In such manner, the objective of this study was to analyze the Brazilian samba influence on PD non-motor symptoms according to the TD and PGID subtypes.

\section{METHODS}

Non-randomized clinical trial with 12 weeks duration, by means of comparison with control group. Approved by the Research Ethics Committee on Human Beings (CEPSH) of UDESC - protocol 1.268.353, with all the participants signatures in the informed consent term.

Individuals with PD members of the Santa Catarina Parkinson Association (APASC) were invited to voluntarily participate in the study and followed the inclusion criteria: clinical diagnosis of PD, according to criteria of the London Brain Bank:19 four months stable medication; of both sexes; age $\geq 50$ years; performing physiotherapy at least once a week; without performing any type of dance for at least three months.

Were excluded, individuals who presented a combined practice of any physical activity schedule and/or physical exercise; who did not complete all study stages (intervention); classified in stage 5 wheelchair users, ${ }^{20}$ who did not reach the cutoff points in the Mini Mental State Examination (MMSE), ${ }_{1}^{21}$ and with physical incapacity for daily living activities or of social life arising from another condition other than PD.

The 23 individuals who accepted to participate in classes formed the experimental group (EG) and were included in the Rhythm and Movement project, took place in partnership with the State University of Santa Catarina and the Catarinense Rehabilitation Center. The mean age was $67 \pm 9.2$ years, with $6.1 \pm 4.4$ years of disease initial manifestation and approximately 2 years until the diagnosis of the disease. The 24 individuals who opted not to participate in the Brazilian samba dance classes became, through consent, automatically from the control group (CG); mean age of $69.6 \pm 9.5$, with $6.9 \pm 6.9$ years of disease initial manifestation and approximately one year until diagnosis.

The experimental group performed the intervention with the Brazilian samba protocol for individuals with PD validated by Tillmann, et al (2016), ${ }^{22}$ and attempted to rigorously carry out the instructions, 
lasting twelve weeks, with two weekly classes of 60 minutes. The activities were divided into warming, main part and relaxation and had a teacher/researcher with knowledge and mastery of the rhythm (samba), besides the aid of three other researchers. To ensure the maintenance of the $C G$, during the intervention period telephone contacts and invitations to monthly lectures on health care were made. At the end of the research both groups received an informative note with the changes and health care tips.

The data collection occurred simultaneously between the groups, both in the initial and final period of the research. We used a questionnaire applied as an individual interview by the researcher composed of validated instruments: Mini Mental State Examination - MMSE21; HY - Degree of Disability Scale; ${ }^{20}$ Unified Parkinson's Disease Rating Scale - UPDRS section 1 * and total values; ${ }^{23}$ Parkinson Disease Questionnaire - PDQ-39:24 Parkinson's Disease Sleep Scale - PDSS; Beck Depression Inventory - BDI:25 Fatigue Severity Scale - FSS ${ }^{26}$ and Magnitude of Perceived Changes. ${ }^{27}$

* In order to obtain results according to study outcomes, only section 1 of the UPDRS we chose to use, designated to the central objective of this study.

The division between groups was made according to the defined algorithms and widely accepted using UPDRS items. For the TD and PIGD designations were used to calculate the medium scores according to original classification, used so the reason between UPRS tremor scores (8 items) and UPDRS PIGD medium scores (5 items). To define patients with TD (reason $<1,5)$, patients with PIGD (reason $<1$ ).

\section{Statistical analysis}

The data were analyzed by the statistical package SPSS - IBM, version 20.0, in which descriptive and inferential statistics were performed. For the initial comparison between the groups, the T-test for independent samples was used, to observe the changes in the pre-and post-intervention moments, and between the groups, the Anova Two-way test with repeated measures and the Sydak comparison test were apply, level of significance of $5 \%$.

After that, the individuals were divided into the two disease subtypes according to the predominant characteristics of the motor phenotype of each in (TD) and (PIGD) and again the Anova Two-way test was performed with repeated measures and Sydak comparison test observing the pre and post-intervention within and between groups.

\section{RESULTS}

The two groups ( $E G$ and $C G$ ) presented at the beginning of the study general and PD characteristics distributed homogeneously and without significant differences between them. They were classified as mild to moderate severity $(1.8 \pm 0.7)$ and mean values were found both in UPDRS (42.3 \pm 18.9$)$ as in QoL (57.2 \pm 25.2). The CG also presented mean values for UPDRS $(51 \pm 21.1)$ and QoL (68.1 \pm 26.9$)$ (data not shown).

Figure 1 shows the groups distribution according to PD subtypes, in which $60 \%$ of the $E G(n=15)$ presented a characteristic of TD whereas in the $C G$ this value was $54 \%(n=13)$, there being no significant differences between groups $(p=0.078)$.

After the twelve weeks intervention, it was observed improvement in all tests scores in EG - without significant changes; the comparison between the groups indicated a significant difference in the UPDRS I post-period $(p=0.020)$ in which the EG group showed cognitive impairment improvement $(C E=0.4)$, whereas the $C G$ presented a deficit in these values ( $C E=-0.4)$.

When observing the results from the subtypes of the disease, after the twelve weeks, a positive change in the values between the individuals of the TD group where find, where only the PDSS did not present significant differences when compared EG to CG. Differences between the pre- and post- $E G$ period on fatigue were significant ( $C E=7.8 / p=0.013)$.

Among individuals who presented PIGD characteristic, no significant changes were observed when compared to the post-period between the $E G$ and $C G$, nor between the pre- and post-EG periods. In the CG, a significant improvement was observed in the scores of depressive symptoms $(C E=4.1 / p=0.041)$. (Table 1)

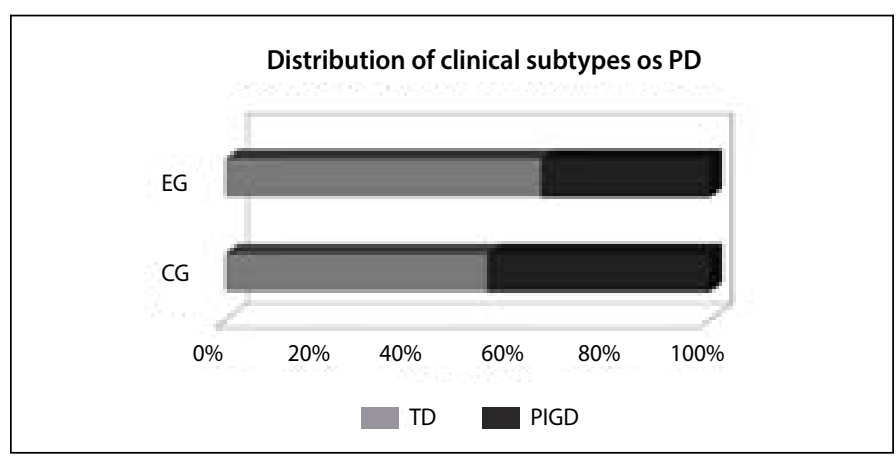

Figure 1. Groups distribution according to PD subtypes, 2016.

Table 1. Comparison of variables after twelve weeks intra-groups and between CG and EG of subjects with PD, 2016.

\begin{tabular}{|c|c|c|c|c|c|c|c|c|c|}
\hline \multicolumn{10}{|c|}{ Total } \\
\hline & \multicolumn{4}{|c|}{ EG } & \multicolumn{5}{|c|}{ CG } \\
\hline PDSS & $88,7 \pm 5,9$ & $96,5 \pm 7,6$ & 7,8 & 0,167 & $75 \pm 5,7$ & $76,7 \pm 7,5$ & 1,5 & 0,761 & 0,069 \\
\hline FSS & $33 \pm 3,6$ & $28,7 \pm 3,6$ & 4,3 & 0,080 & $38,7 \pm 3,6$ & $37,3 \pm 3,6$ & 1,4 & 0,562 & 0,104 \\
\hline UPDRS I & $3,9 \pm 0,5$ & $3,5 \pm 0,6$ & 0,4 & 0,224 & $5,2 \pm 0,6$ & $5,6 \pm 0,6$ & $-0,4$ & 0,340 & 0,020 \\
\hline \multicolumn{10}{|c|}{ TD } \\
\hline PDSS & $87,3 \pm 7,5$ & $93,3 \pm 10,1$ & 6 & 0,471 & $70 \pm 8$ & $70,8 \pm 10,8$ & 0,8 & 0,931 & 0,139 \\
\hline $\mathrm{BDI}$ & $13 \pm 2,7$ & $11,3 \pm 2,8$ & 1,7 & 0,135 & $19,7 \pm 2,9$ & $21,4 \pm 2,9$ & $-1,7$ & 0,156 & 0,020 \\
\hline FSS & $30,3 \pm 4,7$ & $22,5 \pm 4,3$ & 7,8 & 0,013 & $39,7 \pm 5,2$ & $39,2 \pm 4,8$ & 0,5 & 0,899 & 0,016 \\
\hline UPDRS I & $3,5 \pm 0,5$ & $3 \pm 0,7$ & 0,3 & 0,215 & $5,2 \pm 0,7$ & $5,3 \pm 0,7$ & $-0,1$ & 0,847 & 0,030 \\
\hline \multicolumn{10}{|c|}{ PIGD } \\
\hline & \multicolumn{4}{|c|}{$\mathrm{EG}$} & \multicolumn{5}{|c|}{ CG } \\
\hline UPDRS I & $4,7 \pm 1,3$ & $4,3 \pm 1,2$ & 0,4 & 0,619 & $5,3 \pm 1,1$ & $5,9 \pm 1,1$ & $-0,6$ & 0,327 & 0,362 \\
\hline
\end{tabular}


Once the test results showed differences between the subgroups, the perception of the change was made in this division, in order to observe these differences after the intervention (Figure 2). Only one subject with PIGD characteristics did not report improvement after twelve weeks of intervention, whereas among subjects characterized with TD four individuals reported no change in any of the symptoms.

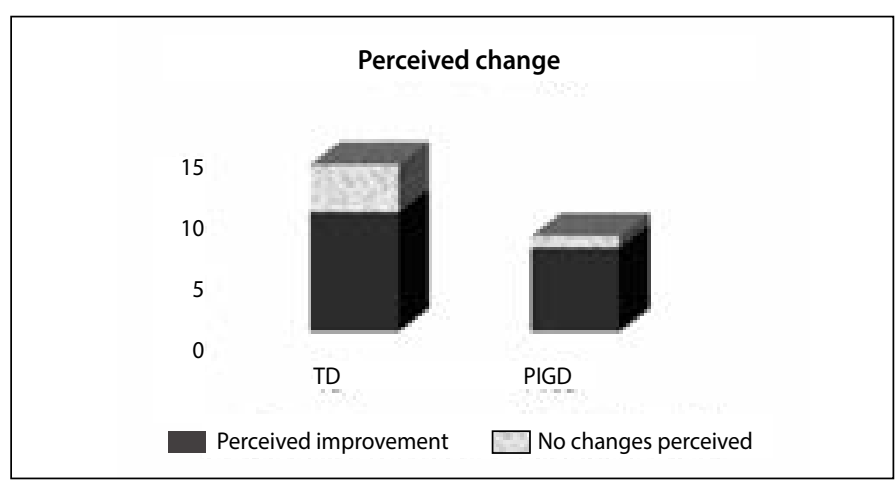

Figure 2. Change in Symptomatology perceived by individuals, 2016.

\section{DISCUSSION}

The main objective of the present study was to analyze Brazilian samba protocol influence on non-motor symptoms of PD and according to the TD and PGID subtypes. Results demonstrate that Brazilian samba influences the maintenance of non-motor symptoms and that the subtypes of PD interfere in the effect of the intervention in individuals. These differences may justify the studies difficulties in reporting non-motor symptoms significant changes after interventions with dance. ${ }^{18}$

In this, the initial comparison performed with the EG and CG identified similar values as the findings in the literature, where EG improved non-motor variables scores, although without significant alterations. A systematic review and meta-analysis combined studies that performed interventions to improve non-motor symptoms $s^{14,18}$ and in all of the 40 studies included in both papers only 4 found significant changes in depressive symptoms; ${ }^{28-30}$ one in fatigue; ${ }^{30}$ and two improvements in daytime sleepiness and cognition. ${ }^{28}$ The possible explanation for the lack of clearer results is due to complexity and interaction of these symptoms with the environment, and with the disease itself. ${ }^{18}$ It is also observed a variety of methodologies, and a limited control both in formulation and application activities, without for example the use of a protocol. ${ }^{18} \mathrm{It}$ is crucial mentioning the importance to include caregivers in different activities, since the patient-caregiver relationship can influence mainly the psychological variables. ${ }^{14}$

In order to understand the variables behavior in the individuals, the analysis was performed according to disease subtypes, and the group's performance was differentiated. When observing the TD group, the Brazilian samba had a strong influence on the results, main change was observed in the fatigue, with significant improvement in EG pre and post- period and between groups in the post-period. Although results in literature point to a trend of improvement in this symptomatology after interventions with dance, significant changes are difficult to find. ${ }^{31}$ Significant changes between the EG and CG were still observed after intervention in depressive symptoms and in the UPDRS section 1 scores (mental behavior and mood).
This improvement may be facilitated for individuals with TD characteristics, since a minor impairment in non-motor symptoms in this group is expected. ${ }^{10}$ Although these changes may reflect the rhythm used, the contagious characteristic of the Brazilian samba rhythm can, like other dances, stimulate practitioners' self-esteem and social relations, reducing the depressive symptoms scores. ${ }^{32}$ The alterations in individual's mental behavior (UPDRS I) can be justified by the possible cerebral areas activation that are no longer stimulated with the advance of PD and due to marked steps and musical stimulation, increasing their activity, resulting in cognitive behavior improvement of these individuals. ${ }^{33}$

In addition, the group with PIGD characteristics presented a different behavior from that expected after the intervention, since there was worsening in $E G$ fatigue scores $(C E=-2,3)$ and a significant improvement in the CG depressive symptoms scores ( $C E=4,1 / p=0,041)$. Individuals classified with this subtype of PD tend to find more difficulty with disease progression, either due to the greater depreciation of symptoms or the greater difficulty in the absorption of Levodopa. ${ }^{8}$ This is because the depreciation and absorption of dopamine tends to be worse in this group, which may have interfered in this study results. Levodopa transforms into dopamine in the brain and thus alleviates neurotransmitter deficiency. However, individuals coexist with side effects of medication such as nausea, vomiting, diarrhea, episodes of akinesia, delusions, dizziness, insomnia, and depression, and it is inevitable that the disease interferes with the routine of the individual, bringing physical and emotional complications, thus triggering social isolation, increasing dependence on activities of daily living, loss of autonomy, leading to a reduction in quality of life. In this way the practice of physical activities promotes the release of endorphin and stimulates the production of dopamine, and this is probably the argument for so many dance interventions success with individuals with PD. ${ }^{31}$

However, in these individuals' samba, as presented, may not be enough to significantly stimulate non-motor symptomatology. Despite the results, it should be noted that when questioned about perceived changes, only one individual reported no improvement in symptoms after twelve weeks, which shows that, notwithstanding statistically, changes by subjects' perceptions were expressive. ${ }^{27}$

One limitation was the sample size that reduces the extrapolating results possibility to other populations, but it shows a reality of the sample surveyed in this region. It is believed that Brazilian samba may be a good option for adjuvant treatment in PD mainly in individuals with TD characteristics. The analyzes performed may also aid the production of more precise interventions for each group and may increase the positive effects on the maintenance of non-motor symptoms in this population.

\section{CONCLUSION}

Finally, it is suggested that new studies involving other dance modalities be performed, in order to provide new possibilities for interventions and directions in relation to practice, aiming to improve other symptoms of PD.

All authors declare no potential conflict of interest related to this article

AUTHORS' CONTRIBUTIONS: Each author made significant individual contributions to this manuscript. ACT (0000-0002-0639-0420**: writing, statistical analysis, intellectual concept and preparation of the entire research project; AS (0000-0002-0535-0208)*: data analysis, writing and revision; AA (0000-0002-6640-9314)* data analysis and revision; JM (0000-00032007-4552)*, LB (0000-0003-4978-9703)* MCSV (0000-0002-7861-7620)*, AEL (0000-0002-1169-6686)*: writing and revision; ACAG (0000-0001-5167-2921)*: writing, revision and preparation of the entire research project. All the authors approved the final version of the manuscript. * ORCID (Open Researcher and Contributor ID). 


\section{REFERENCES}

1. Lees AJ, Hardy J, Revesz T. Parkinson's disease. Lancet. 2009;373(9680):2055-66.

2. Kalia LV, Lang AE. Parkinson's disease. Lancet. 2015;386(9996):896-912.

3. Fan JY, Chang BL, Wu YR. Relationships among depression, anxiety, sleep, and quality of life in patients with parkinson's disease in Taiwan. Parkinsons Dis. 2016;2016:4040185.

4. Skorvanek M, Rosenberger J, Minar M, Grofik M, Han V, Groothoff JW, et al. Relationship between the non-motor items of the MDS-UPDRS and Quality of Life in patients with Parkinson's disease. J Neurol Sci. 2015;353(1-2):87-91.

5. Yarnall AJ, Breen DP, Duncan GW, KhooTK, Coleman SY, Firbank MJ, et al. Characterizing mild cognitive impairment in incident Parkinson disease: the ICICLE-PD study. Neurology. 2014;82(4):308-16.

6. Chahine LM, Amara AW, Videnovic A. Systematic review of the literature on disorders of sleep and wakefulness in Parkinson's disease from 2005 to 2015. Sleep Med Rev. 2017;35:33-50.

7. Zhou HY, Sun Q, Tan YY, Hu YY, Zhan WW, Li DH, et al. Substantia nigra echogenicity correlated with clinical features of Parkinson's disease. Parkinsonism Relat Disord. 2016;24:28-33.

8. Chen HM, Wang ZJ, Fang JP, Gao LY, Ma LY, Wu T, et al. Different patterns of spontaneous brain activity between tremor-dominant and postural instability/gait difficulty subtypes of Parkinson's disease: a resting-state fMRI study. CNS Neurosci Ther. 2015;21(10):855-66.

9. von Coelln R, Shulman LM. Clinical subtypes and genetic heterogeneity: of lumping and splitting in Parkinson disease. Curr Opin Neurol. 2016;29(6):727-34.

10. Wang Z, Chen H, Ma H, Ma L, Wu T, Feng T. Resting-state functional connectivity of subthalamic nucleus in different Parkinson's disease phenotypes. J Neurol Sci. 2016;371:137-47.

11. Ba F, Obaid M, Wieler M, Camicioli R, Martin WR. Parkinson disease: the relationship between non-motor symptoms and motor phenotype. Can J Neurol Sci. 2016;43(2):261-7.

12. Lauretani F, Saginario A, Ceda GP, Galuppo L, Ruffini L, Nardelli A, et al. Treatment of the motor and non-motor symptoms in Parkinson's disease according to cluster symptoms presentation. Curr Drug Targets. 2014;15(10):943-7.

13. Olanow CW, Watts RL, KollerWC. An algorithm (decision tree) for the management of Parkinson's disease (2001): treatment guidelines. Neurology. 2001,56(11 Suppl 5):S1-88.

14. Cusso ME, Donald KJ, Khoo TK. The impact of physical activity on non-motor symptoms in parkinson's disease: a systematic review. Front Med (Lausanne). 2016;3:35.

15. Rios Romenets S, Anang J, Fereshtehnejad SM, Pelletier A, Postuma R. Tango for treatment of motor and non-motor manifestations in Parkinson's disease: a randomized control study. Complement Ther Med. 2015;23(2):175-84

16. Shulman LM, Katzel LI, Ivey FM, Sorkin JD, Favors K, Anderson KE, et al. Randomized clinical trial of 3 types of physical exercise for patients with Parkinson disease. JAMA Neurol. 2013;70(2):183-90.

17. King LA, Wilhelm J, Chen Y, Blehm R, Nutt J, Chen Z, et al. Effects group, individual, and home exercise in persons with parkinson disease: a randomized clinical trial. J Neurol Phys Ther. 2015;39(4):204-12.

18. McNeely ME, Mai MM, Duncan RP, Earhart GM. Differential effects of tango versus dance for PD in Parkinson Disease. Front aging neurosci. 2015;7:239.

19. Hughes AJ, Daniel SE, Kilford L, Lees AJ. Accuracy of clinical diagnosis of idiopathic Parkinson's disease: a clinico-pathological study of 100 cases. J Neurol Neurosurg Psychiatry. 1992;55(3):181-4.

20. Hoehn MM, Yahr MD. Parkinsonism: onset, progression and mortality. Neurology. 1967;17(5):427-42.

21. Bertolucci PH, Brucki SM, Campacci SR, Juliano Y. O mini-exame do estado mental em uma população geral: impacto da escolaridade. Arq Neuropsiquiatr. 1994;52(1):1-7.

22. Tillmann AC, Andrade A, Swarowsky A, Guimarães AC. Brazilian samba protocol for individuals with Parkinson's Disease: a clinical non-randomized study. JMIR Res Protoc. 2017;6(7):e129.

23. Movement Disorders Society Task Force on Rating Scales for Parkinson's Disease. The unified Parkinson's disease rating scale (UPDRS): status and recommendations. Movement Disorders. 2003;18(7):738-50.

24. Souza RG, Borges V, Silva SMCA, Ferraz HB. Quality of life scale in parkinson's disease PDQ-39 - (Brazilian Portuguese version) to assess patientes with and without levedopa motor flutuation. Arq Neuropsiquiatr. 2007;65(3-B):787-91.

25. Beck AT, Ward CH, Mendelson M, Mock J, Erbaugh J. An inventory for measuring depression. Arch Gen Psychiatry. 1961;4:561-71

26. Valderramas S, Feres AC, Melo A. Reliability and validity study of a Brazilian - Portuguese version of the fatigue severity scale in Parkinson's disease patients. Arquivos de Neuropsiquiatr. 2012;70(7):497-500.

27. Gadotti IC, Vieira ER, Magee DJ. Importance and clarification of measurement properties in rehabilitation. Rev Bras Fisioter. 2006;10(2):137-46

28. Modugno N, laconelli S, Fiorlli M, Lena F, Kusch I, Mirabella G. Active theater as a complementary therapy for Parkinson's disease rehabilitation: a pilot study. Scientific World Journal. 2010;10:2301-13.

29. Park A, Zid D, Russell J, Malone A, Rendon A, Wehr A, et al. Effects of a formal exercise program on Parkinson's disease: a pilot study using a delayed start design. Parkinsonism \& Related Disorders. 2014;20(1):106-11.

30. Cugusi L, Solla P, Serpe R, Carzedda T, Piras L, Oggianu M, et al. Effects of a Nordic Walking program on motor and non-motor symptoms, functional performance and body composition in patients with Parkinson's disease. NeuroRehabilitation. 2015;37(2):245-54.

31. Lötzke D, Ostermann T, Büssing A. Argentine tango in Parkinson disease--a systematic review and meta-analysis. BMC Neurol. 2015;15:226.

32. Lee NY, Lee DK, Song HS. Effect of virtual reality dance exercise on the balance, activities of daily living, and depressive disorder status of Parkinson's disease patients. J Phys Ther Sci. 2015;27(1):145-7.

33. Ford JH, Rubin DC, Giovanello KS. The effects of song familiarity and age on phenomenological characteristics and neural recruitment during autobiographical memory retrieval. Psychomusicology. 2016;26(3):199-210. 